\title{
Management of a Mutilated Molar Using Custom Cast Post: A Case Report
}

\author{
Deeksha Khurana ${ }^{1}$, Asha Jetwani $^{2}$, Ashwini B Prasad ${ }^{3}$, Deepak Raisingani ${ }^{4}$
}

\begin{abstract}
Restoration of mutilated teeth is always a challenge in dentistry, especially when coronal structure is inadequate to provide resistance and retention form. The remaining tooth structure must be restored meticulously as it acts as a foundation for the renovation and influences the overall strength of the restored tooth. The classical approach for successful management of such arduous cases would be the utilization of post and core after endodontic therapy with subsequent placement of a full-coverage crown. This case report presents the rehabilitation of badly mutilated mandibular molar using custom-made cast post and core.

Keywords: Cast post, MTA, Mutilated.

Journal of Mahatma Gandhi University of Medical Sciences \& Technology (2021): 10.5005/jp-journals-10057-0182
\end{abstract}

\section{INTRODUCTION}

Endodontic treatment has been in practice for years with a high success rate but postendodontic restoration was not much considered previously. When a tooth is treated endodontically, postendodontic restoration must be considered an important part because endodontic success to a large extent depends on prosthetic rehabilitation. ${ }^{1}$ Extensively mutilated teeth make retention of prosthesis following an endodontic therapy very challenging. The loss of structural integrity due to long-standing caries, trauma, and or overzealous cavity preparation can compromise fracture resistance and resiliency of endodontically treated teeth. ${ }^{2}$ Thus, these teeth are considered more prone to biomechanical failure when compared to vital teeth. ${ }^{3}$

Various methods can be used for reconstructing such mutilated teeth such as custom cast post and core to prefabricated postsystems. ${ }^{4}$ The aim of this procedure is to provide longevity to the core restoration. ${ }^{5}$ The selection of post design is critical when considering the longevity of the tooth. ${ }^{6}$

The custom-designed cast post and core is the traditional recommendation as it closely adapts and approximates the morphology of the prepared canal. $^{5}$

This paper describes a case of a mutilated mandibular second molar that was successfully rehabilitated with custom-designed cast post and core and a splinted metal crown after endodontic therapy.

\section{Case Description}

A 28-year-old male consulted the Department of Conservative Dentistry and Endodontics with the chief complaint of the broken tooth in right lower back tooth region from the past 3-4 years. Intraoral clinical examination revealed grossly decayed tooth number 47 (Fig. 1A). The tooth was nonresponsive to any pulp sensitivity tests and did not elicit pain on percussion. On Radiographic examination (IOPAR) a large coronal and periapical radiolucency was evident in respect to tooth number 47 and tooth number 46 was root canal treated (Fig. 1B). Thus, diagnosis of pulp necrosis with asymptomatic apical periodontitis was made irt tooth number 47 and previously treated with tooth number 46 .

\footnotetext{
${ }^{1-4}$ Department of Conservative Dentistry \& Endodontics, Mahatma Gandhi Dental College \& Hospital, Jaipur, Rajasthan, India

Corresponding Author: Asha Jetwani, Department of Conservative Dentistry and Endodontics, Mahatma Gandhi Dental College \& Hospital, Jaipur, Rajasthan, India, Phone: +91 9461774344, e-mail: ashajetwani333@gmail.com

How to cite this article: Khurana $D$, Jetwani $A$, Prasad $A B$, et al. Management of a Mutilated Molar Using Custom Cast Post: A Case Report. J Mahatma Gandhi Univ Med Sci Tech 2021;6(3):85-88.

Source of support: Nil

Conflict of interest: None
}

Tooth number 47 the concerned tooth here was ideally indicated for extraction but the patient was keen to save the tooth, so the treatment plan decided was the rehabilitation of the tooth with custom-designed cast post followed by a metal crown.

Informed consent was obtained from the patient. Access cavity was prepared and all caries from the pulp floor were excavated in relation to tooth number 47 . Working length was determined using $15 \mathrm{~K}$ ss hand files (Fig. 2A). Thorough cleaning and shaping was done till size F3 ProTaper files with copious irrigation using 2\% chlorhexidine, normal saline, $5 \%$ sodium hypochlorite, and then final rinse with saline. Intracanal dressing of calcium hydroxide dressing was placed for 7 days.

In the next appointment, obturation was done with F3 ProTaper cones using resin-based sealer (Figs 2B and 3A). While excavating caries during access cavity preparation, a very thin layer of dentin remained as caries were almost involving the furcation. So to reinforce the floor, a layer of MTA was placed on pulpal floor (Fig. 3A) (keeping the canals patent) and on the weakened mesial wall as well. It was then covered with moist cotton followed by placement of a temporary restoration.

In the next visit, post space preparation was done in the distal canal with the help of Peeso Reamer up to number $3(1.1 \mathrm{~mm}$ diameter) leaving $5 \mathrm{~mm}$ gutta-percha apically (Fig. 3B). GIC was

(c) The Author(s). 2021 Open Access This article is distributed under the terms of the Creative Commons Attribution 4.0 International License (https://creativecommons. org/licenses/by-nc/4.0/), which permits unrestricted use, distribution, and non-commercial reproduction in any medium, provided you give appropriate credit to the original author(s) and the source, provide a link to the Creative Commons license, and indicate if changes were made. The Creative Commons Public Domain Dedication waiver (http://creativecommons.org/publicdomain/zero/1.0/) applies to the data made available in this article, unless otherwise stated. 

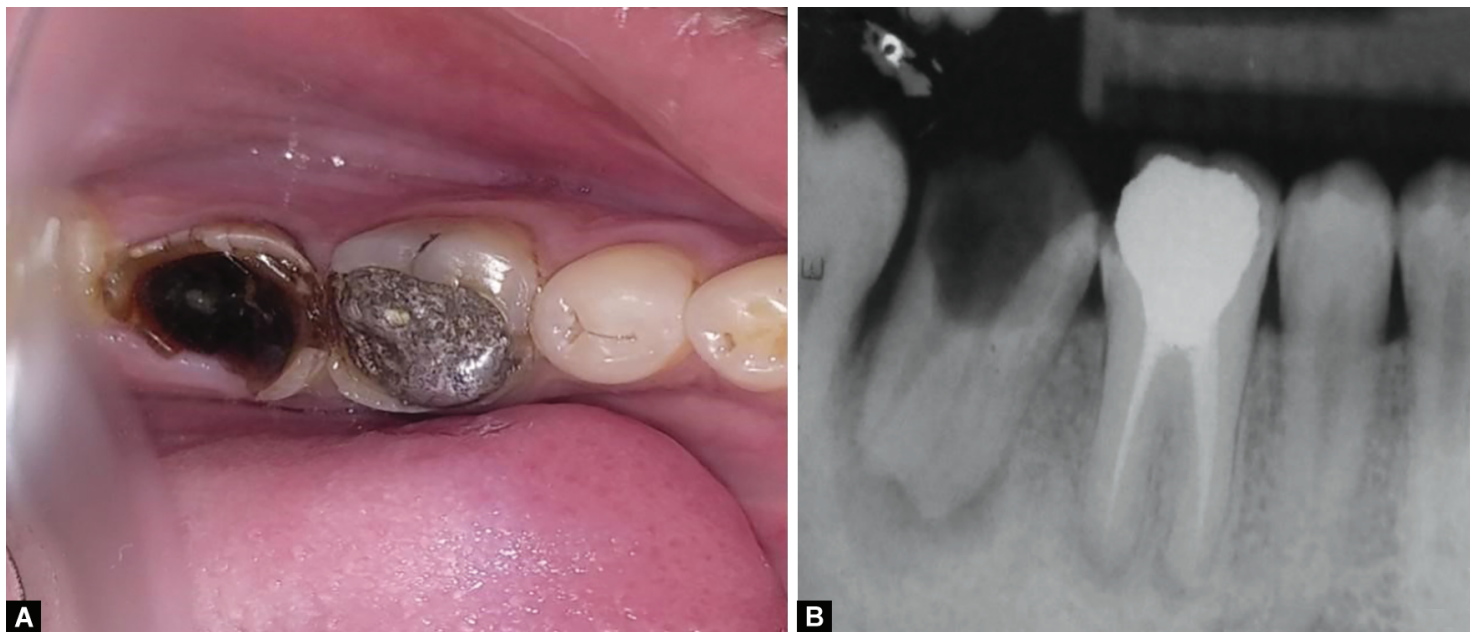

Figs 1 A and B: (A) Preoperative intraoral view. (B) Preoperative radiographic view

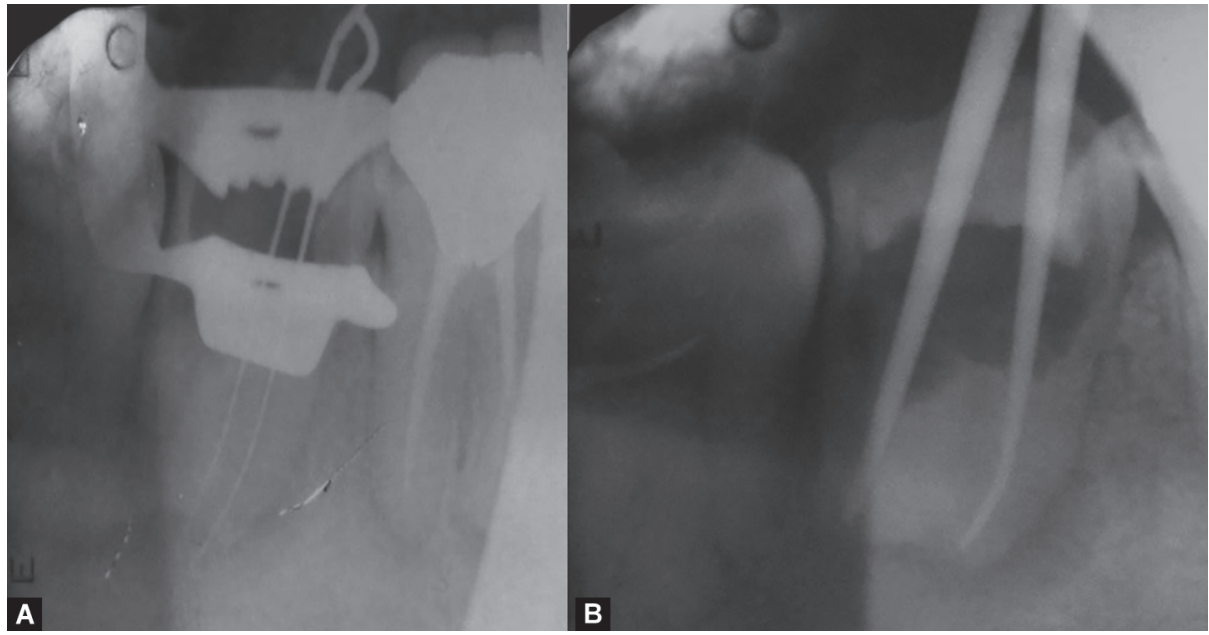

Figs $2 \mathrm{~A}$ and $\mathrm{B}$ : (A) Working length determination. (B) Radiographic image of master cone
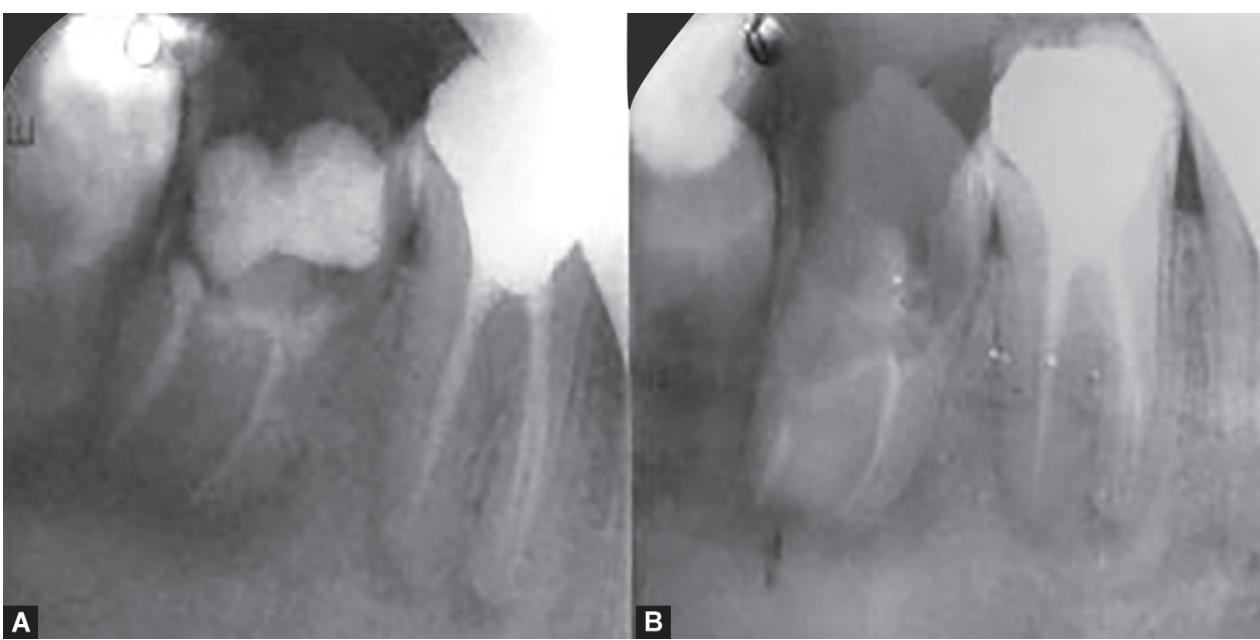

Figs 3A and B: (A) Radiographic view of obturation and a layer of MTA placed on the pulpal floor. (B) Post space prepared

used to smoothen the surface and block any undercuts if present in the access cavity. Then crown preparation for metal crowns with respect to teeth number 46 and 47 was done. Wax pattern for cast post was fabricated in relation to tooth number 47 which was sent to the lab for casting (Fig. 4). In the next appointment cast post and core was luted (Fig. 5) using glass ionomer cement and impression was taken. After two-three days final crown cementation was done with respect to 46,47 (Fig. 6). For better retention splinted metal crowns were fabricated for teeth 46 and 47. Figure 7 shows 1 year follow-up of the case. 


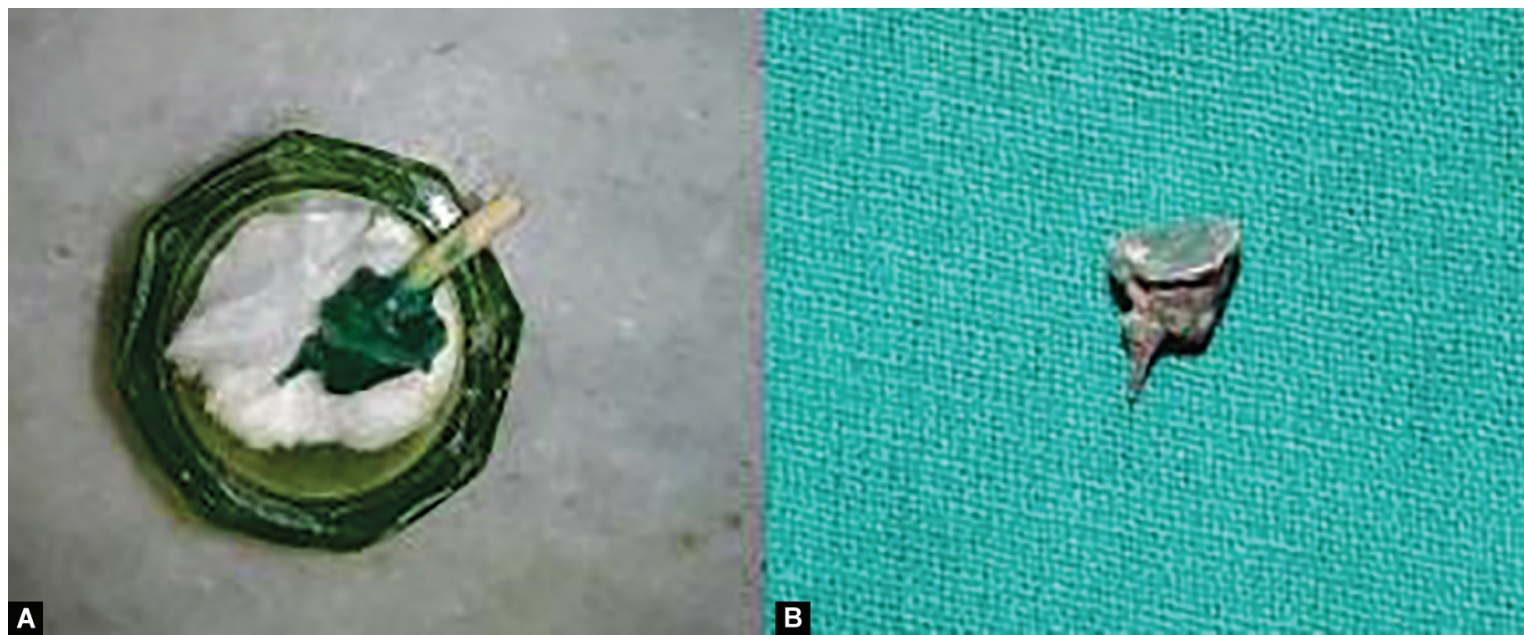

Figs 4A and B: (A) Wax pattern fabricated. (B) Cast post prepared

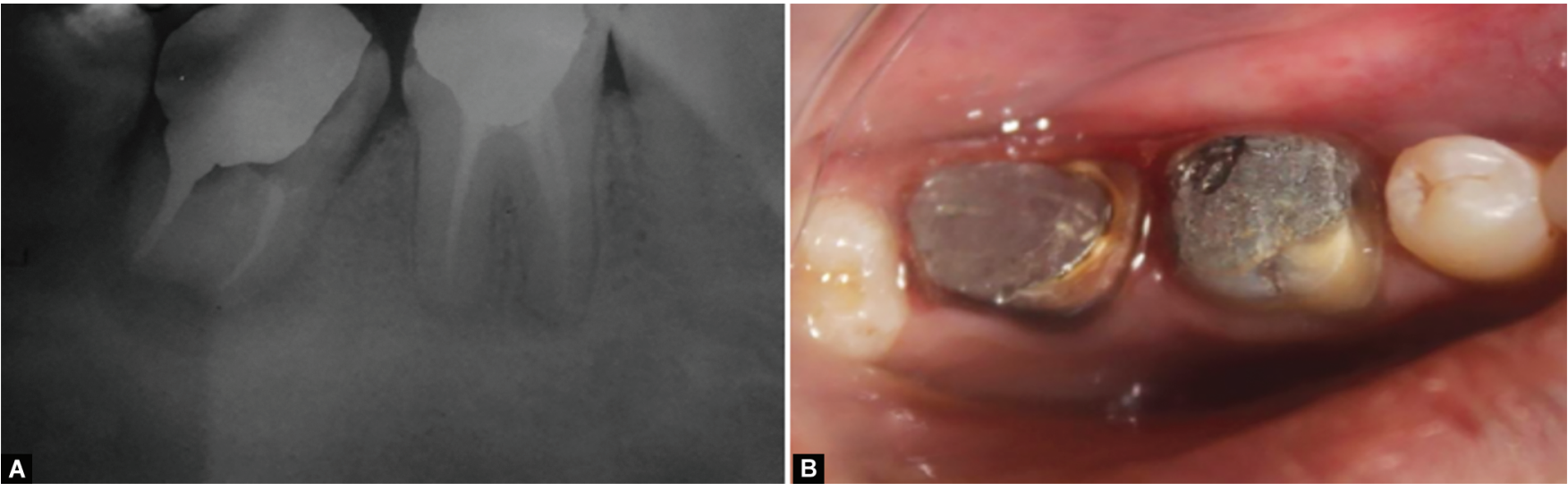

Figs 5 A and B: Luted cast post and core (A) Radiographic view, (B) Clinical view

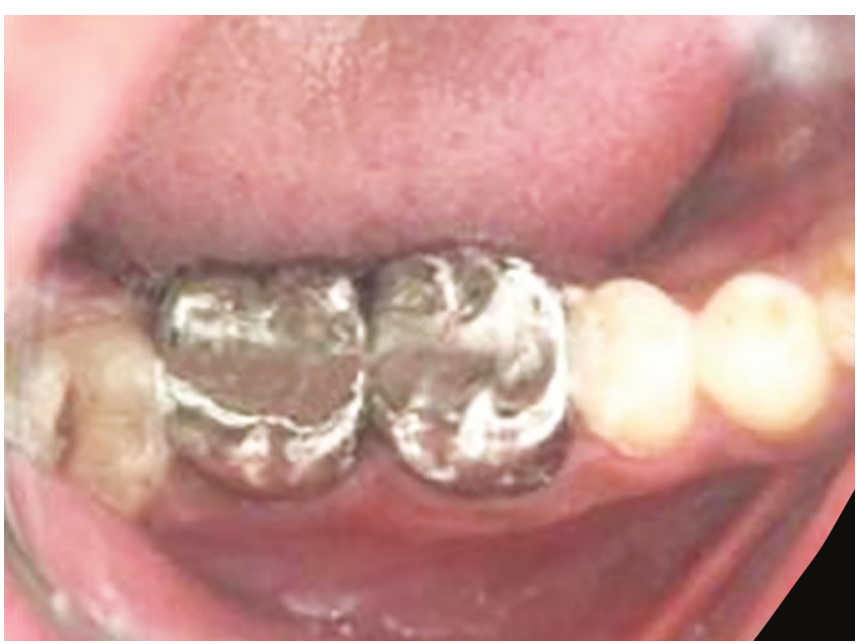

Fig. 6: Crown cementation with respect to teeth number 46 and 47

\section{Discussion}

A tooth is said to be mutilated when it is so badly broken that the remaining tooth structure is not adequate to retain a prosthetic crown. ${ }^{1,7}$ Thus in such cases post can be used to provide the desired retention for the core and placement of a crown. ${ }^{8}$

In the present case, the tooth was grossly destroyed due to caries with insufficient coronal retention for placement of crown.
The treatment modality chosen was custom-made cast post and core over other types of fiber or metal prefabricated post as prefabricated posts show increased failure at the post-core interface. ${ }^{9}$ The custom-made cast post and core prevents the dislodgement of the core from the post as core is an intrinsic part of the post and does not depend on the post for any mechanical retention. ${ }^{10}$ Also cast posts to validate the canal morphology and adapt to all canal configurations. ${ }^{11}$ In a study by Gomez Polo et al., it was found that custom-designed metal posts have higher survival rates of over 10 years. ${ }^{12}$

For individual success, each case must be meticulously assessed clinically. Before establishing the desired post length, the amount of gutta-percha that will remain and the root length must be considered. The recommended postlength is three-fourth of the root length leaving at least $4-5 \mathrm{~mm}$ of gutta-percha apically to ensure an adequate apical seal. Postdiameters should not be more than one-third of the diameter of the root at any location. ${ }^{13}$

The anchorage between the core and the remaining tooth structure is provided by the endodontic post. Thus, as the remaining tooth structure decreases the importance of retention between the post and core increases. ${ }^{6}$

For luting, the endodontic posts various types of cement are used. Some of them are traditional cement like glass lonomer cements, zinc phosphate cement, and resin-based self-adhesive cements. ${ }^{14}$ In the present case, GIC was used for luting the cast post. 

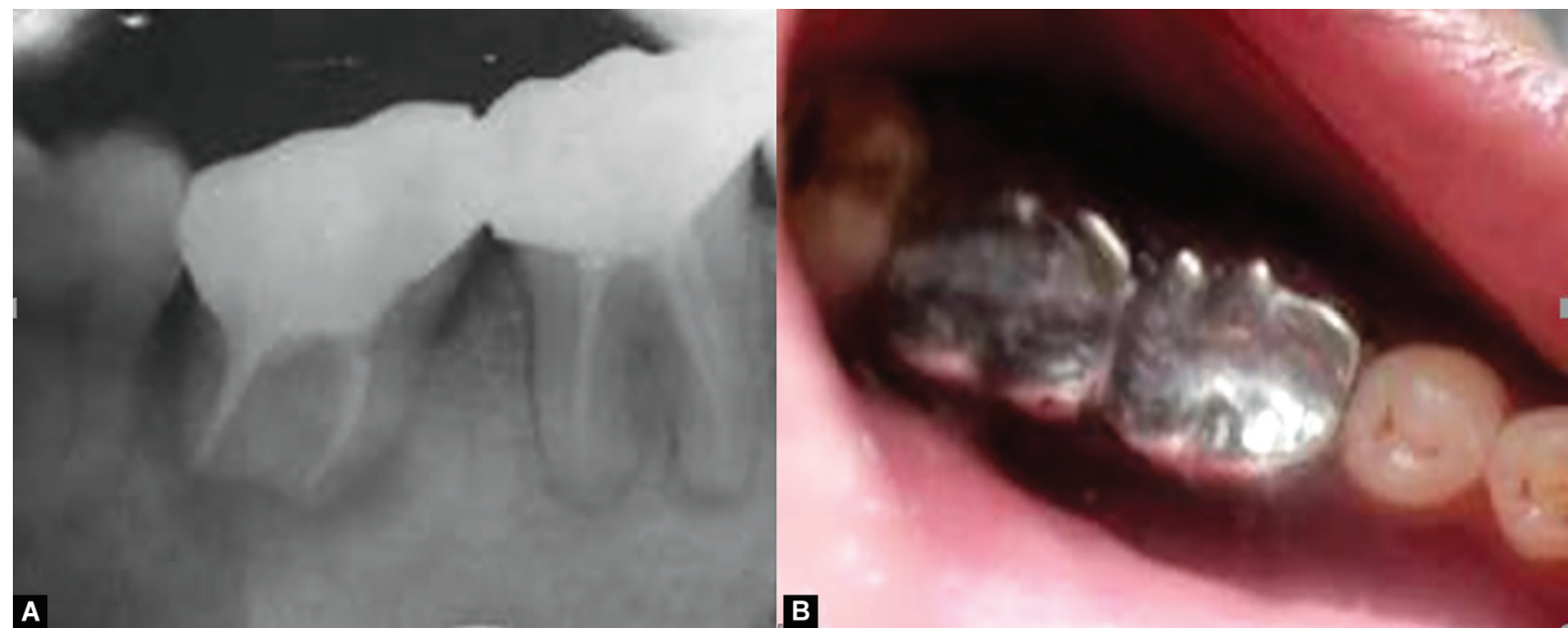

Figs 7A and B: One year follow-up (A) Radiographic view, (B) Clinical view

So, it can be said a comprehensive treatment plan is required before initiating the endodontic therapy which should result in a fully functional prosthetically rehabilitated tooth as a final outcome.

\section{Conclusion}

Selection of right post and core is challenging and should be steered by thorough knowledge about various post core systems and their indications, pros and cons and also keeping in mind the functional requirements and the quality and amount of remaining tooth structure. Cast post and core is a treatment of choice to rehabilitate cases with severe loss of coronal tooth structure and inadequate ferrule. In this case, a functional establishment for the patient has been achieved using custom-designed cast posts and metal crowns.

\section{References}

1. Hegde MN, Ashwini KS. Rehabilitation of mutilated teeth - a systematic review. Acta sci dent sci 2019;3(12):151-156.DOI: 10.31080/ ASDS.2019.03.0717

2. Onofre RS, Castilho R, Boscato J, et al. Cast metal vs. glass fibre posts: a randomized controlled trial with up to 3 years of follow up. J Dent 2014;42(5):582-587. DOI: 10.1016/j.jdent.2014.02.003

3. Chaudhary S, Rathod AA, Yadav P, et al. Restorative management of grossly mutilated molar teeth using endocrown: a novel concept. J Res Dent 2016;4:97-100. DOI: 10.4103/2321-4619.188235

4. Reis JMDSN, Oliveira CRM, Mascaro BA, et al. One-step fiber post cementation and core build-up in endodontically treated tooth: a clinical case report. J EsthetRestor DentInt J Prosthodont 2020;32(1):5-11. DOI: 10.1111/jerd.12551.4) Dhalaan RA, Prosthodontic management of endodontically treated teeth. 2001;1-35.
5. Legha VS, Saini DK, Kumar KVA. Esthetic rehabilitation of mutilated anterior teeth with custom cast post and core porcelain-fused-tometal crowns. Int J Experiment Dent Sci 2015;4(1):69-71. DOI: 10.5005/ jp-journals-10029-1099

6. Morgano SM, Milot P. Clinical success of cast metal posts and cores. J Prosthet Dent 1993;70(1):11-16. DOI: 10.1016/0022-3913(93)90030-

7. Cheung W. A review of the management of endodontically treated teeth. Post, core and the final restoration. J Am Dent Assoc 2005;136(5):611-619. DOI: 10.14219/jada.archive.2005.0232

8. Nayak M, Shenoy V. Endodontic retreatment and rehabilitation of a mutilated mandibular molar using laser surface treated glass fiber post: a case report. Int J Appl Dent Sci 2020;6(2):163-167.

9. Bansal R, Mehrotra N, Chowdhary P, et al. Management of grossly decayed mandibular molar with different designs of split cast post and core. Case Reports in Dentistry 2016;2016:2976941. DOI: 10.1155/2016/2976941.

10. Bora P, Kanodia A, Kataki R, et al. Esthetic rehabilitation of grossly mutilated endodontically treated teeth. Indian J Oral Health Res 2018;4(1):24-26. DOI: 10.4103/ijohr.ijohr_7_18

11. Rajkumar $Y$, Singh A, Halder D, et al. Prosthodontic rehabilitation of endodontically treated traumatized anterior teeth- a case report. Int Res J Pharm Med Sci 2018;1(6):76-77.

12. Gómez-Polo M, Llidó B, Rivero A, et al. A 10-year retrospective study of the survival rate of teeth restored with metal prefabricated posts versus cast metal posts and cores. J Dent 2010;38(11):916-920. DOI: 10.1016/j.jdent.2010.08.006

13. Goodacre CJ, Spolnik KJ. The prosthodontic management of endodontically treated teeth: a literature review. Part 111. Tooth preparation considerations. J Prosthod 1995;4(2):122-128. DOI: 10.1111/j.1532-849x.1995.tb00327.x

14. Joshi TJ, Mistry G, Shetty D, et al. A novel and easy technique for restoring grossly decayed mandibular molar with a modified castpost. Pan Afr Med J 2018;31:129. DOI: 10.11604/pamj.2018.31.129.14394 